Disclosure of Interests: Ertugrul Cagri Bolek: None declared, Emre Bilgin: None declared, Gözde Kübra Yardımcı: None declared, Bayram Farisoğulları: None declared, Emine Duran: None declared, Berkan Armagan: None declared, Levent Kılıç: None declared, Şule Apraş Bilgen: None declared, Ali İhsan Ertenli: None declared, Umut Kalyoncu Consultant of: Abbvie, Amgen, Janssen, Lilly, Novartis, UCB

DOI: 10.1136/annrheumdis-2020-eular.6533

\section{AB0746 EVALUATING TENDER AND SWOLLEN JOINTS FOR THE ASSESSMENT OF INFLAMMATORY PAIN IN PSORIATIC ARTHRITIS USING ULTRASOUND}

P. Bosch ${ }^{1}$, R. Husic ${ }^{1}$, F. Anja ${ }^{1}$, J. Gretler', A. Lackner ${ }^{1}$, W. Graninger ${ }^{1}$ C. Duftner ${ }^{2}$, J. Hermann ${ }^{1}$, C. Dejaco ${ }^{1,3} .{ }^{1}$ Medical University of Graz, Graz, Austria; ${ }^{2}$ Medical University of Innsbruck, Innsbruck, Austria; ${ }^{3}$ Hospital of Bruneck, Bruneck, Italy

Background: Tender and Swollen Joint Counts (TJC, SJC) are items of disease activity scores in rheumatoid arthritis (RA) and psoriatic arthritis (PsA) Recent studies suggest that TJC do not adequately reflect ongoing inflammation in RA when using Ultrasound (US) as a reference standard, and that pain might be due to other, non-inflammatory causes. ${ }^{1,2}$ In PsA, the role of tenderness and swelling of joints for reflecting active inflammation has not been well studied so far.

Objectives: To evaluate tender (TJ) and swollen joints (SJ) for the assessment of inflammation in PsA.

Methods: We performed a prospective study on 83 PsA patients undergoing clinical and ultrasound examinations at two study visits scheduled 12 months apart. Tenderness and swelling were assessed for 68 and 66 joints respectively and US examinations, including grey scale (GS) and power doppler (PD) were conducted at all 68 joints. GS- (range 0-204) und PD sum scores (0-204) were calculated. At patient level, correlations were performed between TJC, SJC and clinical or US values. At joint level a GS value $\geq 1$ and/or PD value $\geq 1$ was defined as active synovitis, which was compared to whether a joint was tender, swollen or both. A generalized linear mixed model was created to assess the predictive value of TJ and SJ for active synovitis after 12 months, taking into consideration the joint site.

Results: At baseline the median TJC and SJC for 83 patients was 4 (range 0-59) and $1(0-20)$, respectively and the median GSS- and PD sum score was 16 (3-56) and 3 (0-31) respectively. SJC correlated with the GSS sum score $(r=0.37$, $p=0.004)$ and PD sum score $(r=0.47, p<0.001)$, while TJC only correlated with PD sum score $(r=0.33, p=0.01)$. TJC correlated better than SJC with patient reported outcomes like patient global assessment (TJC: $r=0.57, p<0.001$; SJC $r=0.39$, $p=0.002$ ) and health assessment questionnaire (TJC: $r=0.50, p<0.001$, SJC no significant correlation). Swollen joints (with or without tenderness) showed active synovitis (GSS $\geq 1$ and/or $P D \geq 1$ ) in $67.6 \%$ of cases, while tender joints (with or without swelling) showed signs of US activation in only $34.5 \%$. A joint that was considered swollen at baseline was more likely to express active synovitis after 12 months (OR: $4.3,97.5 \mathrm{Cl}: 2.9-6.2$ ), compared to a joint that was either tender or swollen at baseline (OR: $2.8,97.5 \mathrm{Cl}: 2.1-3.5)$.

Conclusion: SJC are more closely linked with US signs of inflammation as compared to TJC in PSA. While swelling of a joint predicts US inflammation after a year, the information whether the joint is additionally tender or not, gives no additional predictive information.

References:

[1] Hammer HB, Michelsen B, Sexton J, et al. Swollen, but not tender joints, are independently associated with ultrasound synovitis: results from a longitudinal observational study of patients with established rheumatoid arthritis. Ann Rheum Dis 2019:78:1179-85.

[2] Hammer HB, Michelsen B, Provan SA, et al. Tender joint count may not reflect inflammatory activity in established rheumatoid arthritis patients results from a longitudinal study. Arthritis Care Res (Hoboken) 2018

Disclosure of Interests: None declared

DOI: 10.1136/annrheumdis-2020-eular.4345

\section{$\mathrm{AB} 0747$ \\ SPECIFIC ULTRASOUND LESIONS IN PSORIATIC ARTHRITIS: PREVALENCE AND CORRELATION WITH DISEASE ACTIVITY}

K. Ben Abdelghani ${ }^{1}$, H. Boussaa ${ }^{1}$, S. Miladi ${ }^{1}$, A. Fazaa ${ }^{1}$, K. Ouenniche ${ }^{1}$, L. Souabni ${ }^{1}$, S. Kassab ${ }^{1}$, S. Chekili ${ }^{1}$, A. Laatar ${ }^{1} .{ }^{1}$ Mongi Slim Hospital, Rheumatology, Tunis, Tunisia

Background: Psoriatic arthritis (PsA) is a systemic inflammatory disease with articular and extra-articular features. In recent years, Ultrasonography (US) is playing an important role in the diagnosis and monitoring of this disease. Specific US features of PSA have been reported such as enthesitis, peritenon extensor tendon inflammation (PTI) and soft tissue edema.
Objectives: The aims of this study were to evaluate the prevalence of these US signs in PsA patients and to determine their association with disease duration and activity.

Methods: Patients with peripheral PsA responding to the Classification Criteria for Psoriatic Arthritis (CASPAR) were enrolled. Clinical and biological data were extracted, and then US examination was performed by an experimented rheumatologist blinded to clinical data using a machine type Esaote MyLAb 60 with a linear probe of $6-18 \mathrm{MHz}$. The following US features were evaluated: PTI at the dorsal aspect of metacarpo-phalangeal (MCP) joints, soft edema at the vola aspect of MCP joints and enthesitis of the digitorum extensor at the dorsal aspect of distal inter-phalangeal (DIP) joints.

A $p<0.05$ was considered statistically significant.

Results: We included twenty PsA patients, 8 men and 12 women, with a mean age of $55 \pm 11$ [33-77] years old. The mean disease duration was of $10 \pm 8$ [1-34] years. A family history of PsA or psoriasis was reported in $53 \%$ of cases.

Oral corticosteroids were used in $21 \%$ of patients, at a mean daily posology of $7 \mathrm{mg}$ [5-10] of Prednisone equivalent, Methotrexate in $84 \%$ of cases at a mean posology of $15 \mathrm{mg}$ [10-20] per week, Sulfasalazine in $10 \%$ of cases and a biological DMARD in $32 \%$ of cases (Etanercept=4, Infliximab=1, Adalimumab=1).

The mean number of tender and swollen joints were respectively of $8[0-16]$ and $2[0-8]$. The mean rate of patient global evaluation and visual analogue scale was of $5[0-9]$.

The mean DAPSA (Disease Activity in PSoriatic Arthritis) score was of $32 \pm 27$ [4-112].

US examination demonstrated that all patients had at least one of the three specific signs that we were looking for. At MCP level, PTI was noted in $11 \%$ of joints with Power Doppler (PD) signal in one case and soft tissue edema was noted in $3 \%$ of joints.

At DIP level, enthesitis of digitorum extensor tendon was noted in $39 \%$ of joints. The elementary lesions reported were: enthesophyte in $25 \%$, erosion in $8 \%$, calcification in $5 \%$ and thickened or hypoecoic tendon in $4 \%$ of joints. However, no PD signal was detected at the enthesis.

A positive association was found between DAPSA score and soft tissue edema $(p=0.000)$, but not with PTI (0.668) and enthesitis (0.137). No relation was found between these three lesions and the disease duration.

Conclusion: The presence of soft tissue edema, enthesitis and/or PTI on US can be an argument for the diagnosis of PsA. Soft tissue edema is shown to be associated with disease activity.

Disclosure of Interests: None declared

DOI: 10.1136/annrheumdis-2020-eular.4839

\section{$\mathrm{AB} 0748$}

IMPORTANCE OF COMORBIDITIES IN PATIENTS WITH ARTHRITIS PSORIATIC

I. Braña Abascal' ${ }^{1}$ S. M. Rojas Herrera ${ }^{1}$, M. Priego Fernandez-Martos ${ }^{1}$,

J. Malave Calzada ${ }^{1}$, D. Fernandez Lozano ${ }^{1}$, R. Veroz Gonzalez ${ }^{1}$, J. J. Aznar

Sanchez ${ }^{1}$, E. Chamizo Carmona ${ }^{1} .{ }^{1}$ Rheumatology, Hospital of Mérida, Mérida, Spain

Background: Cardiovascular diseases are more prevalent in inflammatory arthritis, such as psoriatic arthropathy (PsA), than in general population. An increase in the presence of anxiety-depressive disorders has been also described in patients with psoriatic disease.

Objectives: To assess the prevalence of comorbilities in a cohort of patient with PsA, especially cardiovascular events and anxiety-depression disorders.

Methods: Observational, cross- sectional study of a cohort of patients with PsA from a monographic clinical unit in a rheumatology department to describe the presence of comorbidities: hypertension, diabetes, hyperlipemia, hyperuricemia, smoking, obesity, depression and isquemic heart disease (IHD). The

Table 1. Comorbilities in patterns of disease.

\begin{tabular}{lcccc}
\hline & $\begin{array}{c}\text { PsA } \\
(\mathrm{n}=145)\end{array}$ & $\begin{array}{c}\text { Peripheral } \\
\text { disease }(\mathrm{n}=94)\end{array}$ & $\begin{array}{c}\text { Mixed disease } \\
(\mathrm{n}=31)\end{array}$ & $\begin{array}{c}\text { Axial disease } \\
(\mathrm{n}=20)\end{array}$ \\
\hline Age at diagnosis, year (DE) & $45,4( \pm 13)$ & $45,7( \pm 12,9)$ & $45( \pm 13)$ & $43,9( \pm 13,8)$ \\
Time of evolution, years (DE) & $9,3( \pm 6,2)$ & $9,6( \pm 6,5)$ & $8,6( \pm 5,4)$ & $7,3( \pm 2,9)$ \\
Men, $\mathrm{n}(\%)$ & $84(57,9 \%)$ & $48(51,1 \%)$ & $26(83,9 \%)$ & $10(50 \%)$ \\
Women $\mathrm{n}(\%)$ & $61(42,1 \%)$ & $46(48,9 \%)$ & $5(16,1 \%)$ & $10(50 \%)$ \\
Hyperlipemia, $\mathrm{n}(\%)$ & $87(60 \%)$ & $60(63,8 \%)$ & $17(54,8 \%)$ & $10(50 \%)$ \\
BMI >25, n (\%) & $83(57,2 \%)$ & $61(64,9 \%)$ & $15(48,4 \%)$ & $7(35 \%)$ \\
Hypertension, $\mathrm{n}(\%)$ & $46(31,7 \%)$ & $28(29,8 \%)$ & $13(41,9 \%)$ & $5(25 \%)$ \\
Hyperuricemia, $\mathrm{n}(\%)$ & $41(28,3 \%)$ & $25(26,6 \%)$ & $11(35,5 \%)$ & $5(25 \%)$ \\
Diabetes, $\mathrm{n}(\%)$ & $27(18,6 \%)$ & $20(21,3 \%)$ & $6(19,4 \%)$ & $1(5 \%)$ \\
Smokers, $\mathrm{n}(\%)$ & $26(17,9 \%)$ & $13(13,8 \%)$ & $10(32,3 \%)$ & $3(15 \%)$ \\
Depression, $\mathrm{n}(\%)$ & $23(15,9 \%)$ & $16(17 \%)$ & $6(19,4 \%)$ & $1(5 \%)$ \\
Metabolic syndrome $\mathrm{n}(\%)$ & $23(15,9 \%)$ & $15(16 \%)$ & $5(16 \%)$ & $3(15 \%)$ \\
IHD, n (\%) & $15(10,3 \%)$ & $7(7,4 \%)$ & $6(19,4 \%)$ & $2(10 \%)$ \\
\hline
\end{tabular}

